Conclusion The proposed ERR is a sensitive evidence-based tool that summarises essential diagnostic criteria derived from prospective clinical investigations and should be used to identify patients with early stage, active RA. The use of the EER should result in early referral to a rheumatologist for definitive diagnosis and early DMARD treatment, facilitating an improved longterm outcome in these patients.

\section{FRI0046 SIDE EFFECTS OF METHOTREXATE IN THERAPY FOR RHEUMATOID ARTHRITIS ? FIVE YEARS PROSPECTIVE STUDY}

SK Stojanovic, AM Stankovic, JM Nedovic, BN Stamenkovic, AN Dimic. Rheumatology, Institute for Prevention, Treatment and Rehabilitation of Rheumatic and Cardiovascular Diseases? Niska Banja, Medical Faculty, University of Nis, Nis, Yougoslavia

\subsection{6/annrheumdis-2001.1175}

Background Methotexate (MTX) has one of the best efficacy/ toxicity ratios. Toxic effects, rather than lack of response, were the major reason for discontinuing MTX.

Objectives Our aim was to determine the frequency and spectrum of side effects in patients with rheumatoid arthritis (RA) receiving low doses of MTX and eventually to determine existence of risk factors for appearance of side effects.

Methods During five years period, 70 patients with active RA were enrolled in a prospective study. They all fulfilled ARA criteria. There were 54 women and 16 man, between 27 and 76 years. The mean duration of disease was 9,76 \pm 7,58 years. They were treated with low doses of MTX (5 ? 12,5 mg once a week; mean dose 7,5 mg once a week). The mean duration of MTX treatment was 2,82 $\pm 2,27$ years. MTX was given to 27 $(38,57 \%)$ patients without prior treatment with disease modifying antirheumatic drugs. Most of the patients were treated with NSAID and low doses of prednison, according to indications.

Patients with any of the contraindications for MTX (renal, hepatic and pulmonary failure, malignant disease, alcoholism, haematological disorders and uncontrolled diabetes) were excluded from the study. Monitoring of the side effects included radiography of lungs at the beginning of the study and regularly control of complete blood account, urine analyses, liver and renal function.

Results Adverse effects were found in 27 (38,57\%) patients, which required withdrawal of the drug only in $7(10 \%)$ patients. Other adverse effects were transitory and enabled continuation of therapy with dose reduction in $10(14,28 \%)$ patients. The most frequent side effects were gastrointestinal intolerance, in $15(21,43 \%)$ patients, required cessation of therapy in one patient. Four patients had elevated liver enzymes in more consecutive analyses, urging stopping in three cases. Haematological disorders were detected in six $(8,57 \%)$ patients, with trombocitopenia in four and leucopoenia and pancitopenia in rest of two patients. Patient with pancitopenia and one with severe trombocitopenia stopped with therapy. Hypersensitive pneumonitis appeared in one patient, after three months of therapy, with complete resolution after cessation of therapy. One patient had mild herpes zoster infection, which required only transitory withdrawal of the drug.

The adverse effects were seen mostly in the first year of the therapy ?

$18(25,71 \%)$ cases. Also all withdrawals were done in the first year, with cumulative dose from $30 \mathrm{mg}$. to $340 \mathrm{mg}$. (average $204,29 \mathrm{mg}$.). The greatest number of side effects was a registry among the oldest group of patients (from 60 to 80 age) ? 16
$(59,06 \%)$ patients. All three patients with control diabetes shoved some adverse effects.

Conclusion Low dose of MTX is a relatively safe therapy, especially with careful patient selection. Special attention is required for older patients as for patients with diabetes and other risk factors for MTX toxicity. Regular monitoring for side effects is mandatory during the whole period of therapy.

\section{FRI0047 TREATMENT OF RHEUMATOID VASCULITIS WITH INFLIXIMAB}

M Kayser, L Unger, H Nüblein. I. Medizinische Klinik, Krankenhaus Dresden-Friedrichstadt, Dresden, Germany

10.1136/annrheumdis-2001.1176

Background Rheumatoid vasculitis (RV) is a systemic late stage complication in patients with rheumatoid arthritis (RA). Despite cyclophosphamide (CYC) therapy which is the treatment of choice the prognosis is very poor and most patients die within two years.

From our last ten patients with RV who had to be treated by CYC five patients had to stop therapy because of serious complications like infection orcardiac failure. Three patients refractory to CYC were treated with infliximab. A 48 year old male RA patient developed systemic vasculitis with a pericardial effusion, which did not respond to pulse corticosteroids, CYC or even to plasmapheresis. The only way to manage this life threatening condition was to drain the effusion continuously. Infliximab therapy at $3 \mathrm{mg} / \mathrm{kg}$ was initiated. The pericardial effusion as well as all other signs of the systemic vasculitis resolved within two weeks. The second patient, a 62 year old man who underwent abdominal surgery -retrospectively probably because of vasculitisdeveloped vasculitic skin ulcers on the scrotum, the lower legs and in the abdominal wound. Since CYC and methotrexate only lead to a partial remission, infliximab infusions were given. Again, the vasculitic lesions healed. The last case is a 58 year old woman with a more classic RV characterised by crural ulcers. After getting panmyelopathy caused by CYC, infliximab was given and the vasculitic features disappeared. No complications of infliximab therapy occurred although two patients had superinfected skin ulcers.

Our cases show that infliximab is an effective salvage therapy in patients with RV refractory to even CYC. Given the toxicity and complication rate of CYC in this RA patient subset infliximab may well be considered as a first choice alternative to CYC. Objectives

Methods

Results

Conclusion

\section{FRI0048 SIDE EFFECTS OF METHOTREXATE IN THERAPY FOR RHEUMATOID ARTHRITIS ? FIVE YEARS PROSPECTIVE STUDY}

SK Stojanovic, AM Stankovic, JM Nedovic, BN Stamenkovic, AN Dimic. Rheumatology, Institute for Prevention, Treatment and Rehabilitation of Rheumatic and Cardiovascular Diseases? Niska Banja, Medical Faculty, University of Nis, Nis, Yougoslavia

10.1136/annrheumdis-2001.1177

Background Methotexate (MTX) has one of the best efficacy/ toxicity ratios. Toxic effects, rather than lack of response, were the major reason for discontinuing MTX. 
Objectives Our aim was to determine the frequency and spectrum of side effects in patients with rheumatoid arthritis (RA) receiving low doses of MTX and eventually to determine existence of risk factors for appearance of side effects.

Methods During five years period, 70 patients with active RA were enrolled in a prospective study. They all fulfilled ARA criteria. There were 54 women and 16 man, between 27 and 76 years. The mean duration of disease was 9,76 \pm 7,58 years. They were treated with low doses of MTX (5 ? 12,5 mg once a week; mean dose $7,5 \mathrm{mg}$ once a week). The mean duration of MTX treatment was 2,82 $\pm 2,27$ years. MTX was given to 27 $(38,57 \%)$ patients without prior treatment with disease modifying antirheumatic drugs. Most of the patients were treated with NSAID and low doses of prednison, according to indications.

Patients with any of the contraindications for MTX (renal, hepatic and pulmonary failure, malignant disease, alcoholism, haematological disorders and uncontrolled diabetes) were excluded from the study. Monitoring of the side effects included radiography of lungs at the beginning of the study and regularly control of complete blood account, urine analyses, liver and renal function.

Results Adverse effects were found in 27 (38,57\%) patients, which required withdrawal of the drug only in $7(10 \%)$ patients. Other adverse effects were transitory and enabled continuation of therapy with dose reduction in $10(14,28 \%)$ patients. The most frequent side effects were gastrointestinal intolerance, in $15(21,43 \%)$ patients, required cessation of therapy in one patient. Four patients had elevated liver enzymes in more consecutive analyses, urging stopping in three cases. Haematological disorders were detected in six $(8,57 \%)$ patients, with trombocitopenia in four and leucopoenia and pancitopenia in rest of two patients. Patient with pancitopenia and one with severe trombocitopenia stopped with therapy. Hypersensitive pneumonitis appeared in one patient, after three months of therapy, with complete resolution after cessation of therapy. One patient had mild herpes zoster infection, which required only transitory withdrawal of the drug.

The adverse effects were seen mostly in the first year of the therapy?

$18(25,71 \%)$ cases. Also all withdrawals were done in the first year, with cumulative dose from $30 \mathrm{mg}$. to $340 \mathrm{mg}$. (average $204,29 \mathrm{mg}$.). The greatest number of side effects was a registry among the oldest group of patients (from 60 to 80 age) ? 16 $(59,06 \%)$ patients. All three patients with control diabetes shoved some adverse effects.

Conclusion Low dose of MTX is a relatively safe therapy, especially with careful patient selection. Special attention is required for older patients as for patients with diabetes and other risk factors for MTX toxicity. Regular monitoring for side effects is mandatory during the whole period of therapy.

\section{FRI0049 EFFICACY OF LEFLUNOMIDE IN RHEUMATOID ARTHRITIS PATIENTS REFRACTORY TO MULTIPLE DMARDS}

IM Laurindo, CT Borges, JA Kochen, DY Torigoe. Division of Rheumatology, University of São Paulo, São Paulo, Brazil

10.1136/annrheumdis-2001.1178

Background Ineffective control of clinical activity is frequently observed in a subgroup of rheumatoid arthritis (RA) patients that present severe evolution with no response to classical DMARDs isolated or in association.

Objectives To assess the efficacy of leflunomide in difficult RA in a 24-week open-label prospective study.

Methods 20 patients fulfilling ACR diagnosis criteria were selected based on non-response or adverse effects to at least three DMARDS (including methotrexate -MTX). The patients were regularly attending the outpatient clinic for at least 5 years and this study did not bring alterations in their routine care and follow-up. All patients were female, with erosive disease and in clinical activity: mean DAS (disease activity score) $=5.30$. Their mean age was 46 years (range 32 to 61 ) and the mean RA duration was 12 years (range 5 to 27), and FR positive in 19, previous use of at least 3 DMARDs (mean 4; maximum 7). At the beginning of the study chloroquine was currently given to 8 patients, MTX to 13 (mean dose = $19 \mathrm{mg} /$ week; range15-25) and sulfasalazine to 12 . Seven patients were receiving azathioprine and only one was on methilprednisolone monthly pulses. All subjects were receiving oral corticosteroids (CE) (mean 10,5 $\mathrm{mg}$ /day; range 7,5 to $20 \mathrm{mg}$ ) and NSAIDs. While oral dose CE and NSAIDS were maintained, all DMARDS were suspended and Leflunomide administered at the initial dose of $100 \mathrm{mg} / \mathrm{day} /$ 3 days followed by $20 \mathrm{mg} /$ day, with no washout period. Clinical exams and laboratory tests were performed monthly.

Results After 6 months, $60 \%$ of the patients were considered responders achieving ACR $>$ or $=20 \%$. Regarding DAS 28, $75 \%$ of the patients were considered responders. CE oral dose was reduced in 7 patients. Adverse effects were observed in 4 patients: diarrhoea in 2; alopecia in 2. Lymphopenia was observed in one patient who was well controlled (ACR50 response) with leflunomide every other day. Only one patient suspended treatment (alopecia plus clinical activity). There was no increase in transaminase enzymes levels. Increase in alkalyne phosphatase levels was observed in 5 patients: in four, increase was mild $(<2$ times that of normal range) and in only one $>$ or $=2$ times that of normal range.

\begin{tabular}{|c|c|c|c|c|}
\hline $\begin{array}{l}\text { Clinical parameters and ESR } \\
\text { (mean } \pm \mathrm{sd} \text { ) }\end{array}$ & $\begin{array}{l}\text { Initial }(\mathbf{n}= \\
20)\end{array}$ & $\begin{array}{l}\text { Final }(n= \\
20)\end{array}$ & $\%$ & $\begin{array}{l}\mathrm{p}<0.05 \\
\text { (paired T } \\
\text { test) }\end{array}$ \\
\hline Swollen joint count & $9 \pm 4$ & $4 \pm 4$ & 59 & $p=0.000$ \\
\hline Tender joint count & $12 \pm 8$ & $4 \pm 6$ & 64 & $p=0.001$ \\
\hline Pain - VAS - 0-100 mm & $56 \pm 29$ & $26 \pm 21$ & 54 & $p=0.000$ \\
\hline $\begin{array}{l}\text { Global evaluation patient }-0-100 \\
\mathrm{~mm}\end{array}$ & $59 \pm 28$ & $29 \pm 25$ & 43 & $p=0.002$ \\
\hline HAQ & $1.44 \pm 0.73$ & $0.65 \pm 0.63$ & 55 & $p=0.000$ \\
\hline ESR & $49.3 \pm 22.1$ & $39.5 \pm 22.7$ & 20 & $p=0.09$ \\
\hline DAS 28 & $5.30 \pm 0.79$ & $3.77 \pm 1.03$ & 28 & $p=0.000$ \\
\hline
\end{tabular}

Conclusion Patients refractory to multiple DMARDS can safely achieve a favourable response with leflunomide. 